\title{
Corpo, natureza e cultura: contribuições para a educação*
}

\author{
Maria Isabel Brandão de Souza Mendes \\ Terezinha Petrucia da Nóbrega
}

Universidade Federal do Rio Grande do Norte, Programa de Pós-Graduação em Educação

\section{Introdução}

A educação, ao se pautar nos pressupostos racionalistas da modernidade, tenta instituir códigos morais que ditam as condutas, reprimindo, dessa maneira, as possibilidades diversas de expressão do corpo. Estabelece um distanciamento entre a aprendizagem e as experiências sensíveis, fato este explicado pelo desejo de querer um mundo durável de uma razão que quantifica, mede e que considera os sentidos como enganadores.

* Artigo apresentado, em versão preliminar, na $26^{\mathrm{a}} \mathrm{Reu}-$ nião Anual da ANPEd, realizada em Poços de Caldas, MG, de 5 a 8 de outubro de 2003. As autoras agradecem aos professores do Núcleo de Estudos e Pesquisas em Educação, Ciência e Tecnologia (NEPECT), pelos debates que contribuíram para a pesquisa de mestrado intitulada Corpo e cultura de movimento: cenários epistêmicos e educativos, que deu origem a este artigo. Agradecem também ao Grupo de Trabalho de Filosofia da Educação pela oportunidade de discussão do trabalho após a apresentação, e às sugestões do parecerista da Revista Brasileira de Educação.
A educação ainda recebe fortes influências do pensamento cartesiano, que, através de uma visão dualista, tem como fundamentos: axiomas matemáticos, ordem e leis da mecânica. O corpo humano, ao ser comparado com uma máquina hidráulica, recebe uma educação que o considera apenas em seu aspecto mecânico, sem vontade própria, sem desejos e sem o reconhecimento da intencionalidade do movimento humano, o qual é explicado através da mera reação a estímulos externos, sem qualquer relação com a subjetividade. O pensamento de Descartes, fundado no exercício do controle e no domínio da natureza, influencia a educação através da racionalização das práticas corporais. Ao ter como princípios a utilidade e a eficiência, busca-se a padronização dos corpos, e os gestos vão sendo controlados, embasados na racionalidade instrumental (Nóbrega, 2000).

Desse modo, no intuito de problematizar as oposições inconciliáveis, a proposição desta reflexão é discutir a construção teórica da relação entre corpo, natureza e cultura através de aproximações epistemológicas entre as ciências naturais, humanas e a filosofia, e apontar contribuições para a educação. 


\section{Corpo, natureza e cultura}

Corpo natural ou cultural? Corpo humano ou animal? Corpo universal ou singular? Com tantas inquietações, buscamos para esta discussão contribuições para a compreensão da relação entre corpo, natureza e cultura por meio de referências disciplinares que tecem diálogo com outras áreas do conhecimento, principalmente através dos estudos de MerleauPonty, Maturana, Varela, Lévi-Strauss e Morin. Destacamos que não tivemos a intenção de fazer a exegese da obra desses autores, mas sim, de buscar pistas e possibilidades de compreender a relação em questão.

Ao refletirmos, então, sobre as transformações epistêmicas que vêm ocorrendo ao longo do século $\mathrm{XX}$, percebemos que na biologia essas mudanças ocorreram quando passaram a considerar que organismo e ambiente coexistem, ultrapassando a controvérsia vitalismo-mecanicismo. ${ }^{1}$ Até os anos de 1950, a biologia restringia-se à fisiologia, uma vez que se mantinha fechada para o universo físico-químico, conseqüentemente, fechada para o fenômeno social, que, "embora espalhado muito no reino animal, e até no vegetal, apenas era percebido, por falta de conceitos adequados, sob forma de tênues semelhanças" (Morin, 1973, p. 19). Surge, portanto, na segunda metade do século XX, a abordagem sistêmica. Nessa nova concepção da biologia, a natureza é considerada novamente viva e passa a compreender que organismo e ambiente coexistem, transformando as concepções que acreditavam serem os genes os únicos responsáveis pela formação do ser vivo.

1 O vitalismo é uma teoria que concebe os organismos vivos como realmente vivos, animados, porém, restringe a vida aos organismos biológicos, deixando o restante da natureza aos cuidados da física mecanicista. O mecanicismo é uma teoria que considera os organismos como máquinas inanimadas que são governadas pelas leis gerais da natureza, referindo-se aos processos físico-químicos, atribuindo, portanto, as características dos organismos exclusivamente aos genes (Sheldrake, 1991).
Nessa perspectiva, o conceito de vida que os biólogos Humberto Maturana e Francisco Varela (2001) propõem é de um processo denominado autopoiesis. Um organismo vivo, ou seja, autopoiético, é capaz de se autogerar ininterruptamente. A Teoria da Autopoiese estuda os seres vivos a partir de suas relações com o entorno, propondo o entrelaçamento entre as ações biológicas e os fenômenos sociais. ${ }^{2}$ Os seres vivos, possuindo organização autopoiética, são capazes de se autoproduzirem continuamente, especificando seus próprios limites, à medida que interagem com o meio em que vivem. Portanto, nota-se que autonomia e dependência se complementam, deixando de ser pólos opostos que não se conciliam.

Na segunda metade do século XX também ocorrem transformações na antropologia, quando Claude Lévi-Strauss publica a obra As estruturas do parentesco. ${ }^{3}$ Nesse estudo, o autor, ao tecer críticas à antítese entre natureza e cultura que era preconizada pela sociologia através de métodos de investigação que procuravam isolar esses fenômenos, tem como propósito substituir as antinomias por relações de complementaridade.

Das contribuições do referido autor, apontam-se os dois aspectos significativos para a compreensão dos conceitos de corpo, natureza e cultura, a saber: a passagem da ordem da natureza à cultura e a crítica à hierarquização cultural. Ao recusar a idéia de que os homens tenham vivido somente em estado de natureza, Lévi-Strauss (1976) compreende que até mesmo o homem de Neandertal não pode ter sido caracterizado como vivendo em estado de natureza, por já possuir cultura. Entretanto, para ele, não existem possibilidades de saber em que momento os fatos naturais se transformam em culturais, mas somente como eles

\footnotetext{
2 O entrelaçamento entre as ações biológicas e os fenôme-
} nos sociais, nesse estudo de Maturana e Varela, ocorre no nível da linguagem, não levando em consideração o nível econômico, nem o político.

${ }^{3}$ Obra publicada em 1949, um ano após ter sido apresentada e defendida na versão original como tese na Sorbonne (Pontes, 1999). 
se articulam. Para tanto, busca no que é universal o critério de natureza, e em tudo o que está ligado a uma norma específica, a uma regra, busca o pertencimento à cultura. Isso nos faz reconhecer que os gestos podem ser considerados campo de visibilidade da articulação entre natureza e cultura. Portanto, apesar de todos os seres humanos serem capazes de gesticular, os gestos expressam as singularidades individuais e culturais apresentando linguagens específicas. Essa articulação, ao mesmo tempo em que contribui para refutar o reducionismo referente à naturalização do corpo e do movimento humano, revelando os aspectos culturais e sociais, expõe algo que é comum a todos os seres humanos, ou seja, a linguagem gestual.

Dessa maneira, no intuito de problematizar a ruptura entre natureza e cultura, Lévi-Strauss (1983) se opõe à antropologia que separa os aspectos biológicos dos aspectos sociais e psicológicos, mostrando que a colaboração dos estudos desenvolvidos entre geneticistas e etnólogos demonstra que as relações entre evolução orgânica e cultural são análogas e complementares; suscita que não há aptidões inatas, como preconizavam as teorias fundamentadas pelos estudos biológicos, as quais compreendiam as desigualdades sociais como sendo naturais.

Ao rejeitar o relativismo cultural e sua conseqüente oposição entre humanidade e animalidade, natureza e cultura, Lévi-Strauss (1983) critica a hierarquização das culturas e defende que essa posição não é concebível, justamente pelo fato de que nenhuma cultura é melhor do que outra. E é justamente na originalidade de cada uma que somos capazes de assistir ao que é universal entre elas, pois todos os homens, ao tentarem resolver seus problemas e perspectivar valores, procuram utilizar o que é comum entre os seres humanos, como a linguagem, as técnicas, a arte, os conhecimentos, as crenças religiosas e a organização social, econômica e política, que vão variando conforme as necessidades específicas. A partir do pensamento desse autor, percebe-se que as singularidades de cada cultura não deveriam ser utilizadas para justificar as desigualdades sociais, nem tampouco ser motivo de impedimento para a comunicação entre as diversas culturas existentes no mundo.

Desse modo, as aproximações entre os campos epistemológicos das ciências naturais e humanas, para além do mecanicismo e do determinismo natural e cultural, apontam possibilidades de problematizar a concepção de corpo como máquina, concepção esta pautada na causalidade linear, bem como problematizar as oposições inconciliáveis, o isolamento entre corpo e mundo, em que o ser humano se mantém afastado da natureza. Tais aproximações entre os campos disciplinares da biologia e da antropologia ${ }^{4}$ fazemnos perceber semelhanças com os pressupostos filosóficos propostos por Merleau-Ponty (1991) nos seus estudos sobre o corpo. $\mathrm{O}$ autor tece críticas à ruptura natureza-cultura presente nas áreas do conhecimento que não dialogam entre si, fazendo uma ressalva ao fato de as explicações sociológicas não estabelecerem comunicação com qualquer tipo de explicação das ciências naturais e vice-versa.

Merleau-Ponty (2000), ${ }^{5}$ ao abordar a natureza diferentemente de como esta vinha sendo concebida nas

4 Em relação aos estudos antropológicos, Merleau-Ponty, ao perceber inovações no trabalho de Lévi-Strauss referente aos objetos etnológicos, redige o artigo "De Mauss a Claude LévyStrauss", publicado pela primeira vez em 1959, na Nouvelle Revue Française, e no ano posterior no livro Signes, traduzido para o português em 1980. Neste ensaio, Merleau-Ponty defende a criação da cátedra de Antropologia Social no Collège de France, na qual Lévi-Strauss conseguiu ser eleito em 1960, após duas tentativas sem êxito (Pontes, 1999).

Em relação aos estudos biológicos, a Teoria da Autopoiese proposta pelos biólogos Humberto Maturana e Francisco Varela recebe contribuições dos estudos de Merleau-Ponty, em especial da experiência vivida. Esta é tida por Varela como fundamental para conceber a crítica feita por esta teoria ao fenômeno mental da consciência (Maturana \& Varela, 1997).

5 Essa edição, apesar de ter sido publicada no Brasil no ano 2000, compõe-se de transcrições de cursos dados pelo filósofo Merleau-Ponty no Collège de France durante os anos de 1957 a 1960. 
ciências naturais, reduzida meramente ao conjunto dos objetos dos sentidos, afirma que "a natureza é um objeto enigmático, um objeto que não é inteiramente objeto; ela não está inteiramente diante de nós. É o nosso solo, não aquilo que está diante, mas o que nos sustenta" (p. 4).

Para esse filósofo, o intuito de um aprofundamento sobre os estudos da natureza que realizava no Collège de France estava relacionado à necessidade de maiores esclarecimentos, uma vez que não concordava com a idéia de natureza verdadeira e imutável, concebida por Descartes. A concepção cartesiana, ao compreender que a natureza não é viva, concebea como matéria inanimada, criada e controlada por Deus através de leis mecânicas exteriores. Tais leis, embasadas na matemática e na física clássica, eram responsáveis por moldar o corpo humano, para que este fosse reconhecido. Merleau-Ponty (2000), ao contrapor-se a essa concepção, considera a natureza viva. Reconhece que a sua relação com o ser humano é recíproca e de co-pertença. Uma relação dinâmica, na qual a própria natureza é capaz de esclarecer sobre a nossa relação conosco e com os outros seres. O conceito de natureza viva proposto por Merleau-Ponty assemelha-se à concepção de natureza que vem sendo redescoberta pela ciência.

Nesse sentido, a natureza considerada orgânica, espontânea e criativa, problematiza a teoria mecanicista da natureza, concebendo-a como autoorganizadora. Essa compreensão de natureza viva é influenciada pelo pensamento mítico e recebeu respaldo quando os astronautas e os cosmonautas puderam visualizar o planeta Terra a partir do espaço, percebendo-o como um todo integrado (Sheldrake, 1991).

A natureza considerada viva, em constante transformação, possui caráter polissistêmico, ou seja, é formada pela solidariedade de vários sistemas encadeados, que, ao se imbricarem, são interdependentes. Nessa relação, o ser humano, constituído por sistemas celulares, "faz parte dum sistema social, no seio dum ecossistema natural, que por sua vez está no seio dum sistema solar, que por sua vez está no seio dum sistema galáctico" (Morin, 1977, p. 97). Nesse sentido, o homem, ao fazer parte dessa totalidade complexa, retoma a idéia de que o ser humano é natureza, problematizando as teorias que o consideram superior.

Encontramos também nos estudos etológicos contribuições para refutar a compreensão de que o ser humano é superior no mundo vivo. O homem, ao descobrir que os animais se comunicam, que possuem rito e símbolo, reconhece que essas características não são exclusividades humanas (Morin, 1973). Portanto, o homem surge a partir da natureza, devendo ser considerado, além de inerente a ela, inerente ao mundo e inerente à animalidade. A distinção entre o homem e os outros animais ocorre pela diferença existente entre os corpos. Cada animal possui um mundo que lhe é específico, e a vida é compreendida através de uma abertura de um campo de ações em que cada animal, ao mesmo tempo em que é criado por ele, é capaz de criá-lo de acordo com a temporalidade e espacialidade próprias. Mundo de seres vivos diferenciados, percepções diversas, como aponta MerleauPonty (2000).

Percebemos que os investimentos de MerleauPonty (2000) nos estudos sobre o comportamento animal aproximam-se dos estudos etológicos realizados por Cyrulnik (1997), quando se mostram contrários às concepções que hierarquizam o ser humano na escala dos seres vivos, uma vez que ambos atribuem a cada animal uma espacialidade e forma do corpo específica. Ao realizar a etologia comparativa, este autor analisa os comportamentos animais e os humanos, mostrando a diferença entre eles, por acreditar que, ao descrever as diferenças, possa encontrar o que há de comum. Cada animal está ligado a um mundo particular correspondente a sua morada. "Um mundo de ratos não é um mundo de homens, que não é um mundo de ouriços-do-mar. Estes três seres vivos, colocados dentro de uma mesma ecologia biofísica, perceberão significados materiais diferentes. O objeto portador de significado 'alimento' é muito olfativo no rato, mais visual no homem e quimiotáctil 
no ouriço-do-mar" (Cyrulnik, 1997, p. 21). Essas diferenças ocorrem devido às percepções variadas que cada corpo é capaz de proporcionar.

Desde que nascemos, então, nosso corpo traz a história que nos concebe como indivíduos da espécie humana. Espécie humana universal, perpetuada graças à interação entre indivíduos de grupos diferentes, responsável pela diversidade individual e étnica, como propõe a Teoria da Exogamia, ${ }^{6}$ demonstrando que a diversidade é fundamental para a manutenção dos seres humanos (Lévi-Strauss, 1976).

A existência de cada organismo inicia-se com uma célula, a qual possui certas estruturas iniciais, e esta estrutura inicial é resultado da história da filogenia. Dando continuidade à historicidade do corpo, vamos construindo outra história mediante nossas experiências de vida, de acordo com a sociedade em que vivemos. Nosso corpo humano possui a mesma organização dos seres vivos, porém, com estrutura diferente, vai adquirindo originalidade à medida que vai interagindo com o entorno. A história de mudanças na estrutura de um organismo em interações com o meio, ou seja, a ontogenia, é denominada de deriva estrutural. Nesta,

[...] as mudanças estruturais que ocorrem são contingentes com as interações com o meio. Não são determinadas pelas circunstâncias do meio, mas são contingentes com elas, porque o meio apenas desencadeia no ser vivo mudanças estruturais. E vice-versa: o meio muda de maneira contingente com as interações com o organismo. (Maturana, 2001, p. 82)

Formado por uma dinâmica molecular, o corpo vai organizando-se e se reorganizando mediante as provocações advindas do ambiente, das pessoas e da

${ }^{6}$ A Teoria da Exogamia mostra que os indivíduos, ao passarem a se casar com pessoas pertencentes a grupos distintos dos seus, diminuíram os cruzamentos consangüíneos, sendo responsáveis por perpetuar a espécie humana. sociedade com as quais convivemos, sendo ao mesmo tempo agente perturbador, modificando-as.

Nosso corpo possui historicidade tanto na estrutura orgânica quanto nas interações com a cultura em que vamos convivendo, o que desmistifica a idéia de que só os estudos culturais reconhecem a historicidade do corpo. Desse modo, a biologia passa a reconhecer as diversidades individuais e culturais, desautorizando, portanto, a idéia da mundialização de um corpo padrão.

A historicidade do corpo faz com que haja modificações e nossos gestos adquiram significados novos mediante as experiências que vão ocorrendo. E é através desses gestos que somos capazes de expressar muitos desses símbolos e esconder outros, formando, portanto, a linguagem do corpo; o corpo está sempre se reorganizando. E por possuir espacialidade e temporalidade próprias, cada corpo vai adquirindo percepções de acordo com o mundo que lhe é específico. Cada corpo mantém relações com o espaço em que está inserido, com os outros animais, seja da mesma espécie ou de espécies diferentes. O comportamento simbólico é inseparável dos esquemas inatos, uma vez que o modo como o animal faz uso do seu corpo para beber, para se alimentar ou até mesmo para a função da excreção, é sempre acompanhado de um cerimonial, variando, enfim, conforme as espécies (Merleau-Ponty, 2000).

Podemos perceber essa inseparabilidade do comportamento simbólico e dos esquemas inatos quando Baitello Junior (1999) refere-se a um quadro clínico de afecções masculinas, relatando que o paciente fala para o médico que o seu jato de urina não tem mais força, ou que só consegue urinar sentado, situação pela qual nunca imaginou passar. Nesse sentido, o urinar longe demonstra o imaginário masculino da potência e do poder. A própria urina "constitui-se um texto da cultura, tão prenhe de significados e histórias que se foram juntando ao próprio objeto, de maneira que sua complexidade cresce permanentemente, desde suas origens animais, passando por seu percurso mítico-religioso e ritual, aos quais se somam os conhecimentos científicos" (p. 117). 
Portanto, os conceitos de vida, de animal, de homem e de cultura não podem ser considerados inflexíveis. É preciso conceber a interação de sistemas complementares, concorrentes e antagonistas, como o sistema genético, o cérebro, o sistema sociocultural e o ecossistema. ${ }^{7}$ Nesse sentido, o ser humano é um ser vivo complexo, uno e múltiplo simultaneamente, que faz parte de um tempo considerado uno e múltiplo também, do qual, além de ser o produto, é o produtor. Corpo multidimensional, que além de ser técnico e racional, é mítico, festivo, dançante, capaz de sentir e provocar êxtase, amor e guerra (Morin, 1973). O homem é considerado um ser biocultural, sendo totalmente biológico e totalmente cultural, pois tudo o que é humano possui ligação com a vida. A respeito dessa relação, Morin mostra que:

[...] a afetividade, a inteligência, o espírito humano, provenientes duma evolução animal e duma ontogénese biológica, constituem realidades vivas e vitais. A própria cultura é o fruto duma evolução biológica e, dependente da sociedade humana, depende da auto-(geno-feno-ego)-ecore-organização social.

Mas, ao mesmo tempo, a cultura é uma emergência propriamente metabiológica, irredutível enquanto tal, produzindo qualidades e realidades originais, e que retroage enquanto tal sobre tudo o que é biológico no homem. (1980, p. 387)

Desse modo, corpo, natureza e cultura se interpenetram através de uma lógica recursiva. O que é biológico no ser humano encontra-se simultaneamente infiltrado de cultura. Todo ato humano é biocultural.

Os gestos, considerados bioculturais, expressam a nossa própria vida individual e coletiva porque têm um sentido histórico. As dimensões históricas, por não serem consideradas imutáveis, mostram que a inten-

${ }^{7}$ Ecossistema é o sistema composto pela flora, fauna e fatores físico-químicos de uma comunidade e as inter-relações entre estes (cf. glossário de termos de ecologia da Academia de Ciências do Estado de São Paulo, 1980). cionalidade dos gestos expressa a maneira única de existir no ato do momento vivido, uma vez que o corpo humano, por estar atado ao mundo através de uma relação dinâmica, atribui sentidos que se renovam conforme a situação. Portanto, em relação à história, "não há uma palavra, um gesto humano, mesmo distraídos ou habituais, que não tenham significação" (Merleau-Ponty, 1999, p. 16).

Os gestos vêm sendo estudados, também, a partir dos anos de 1970, pela semiótica da cultura, como sendo textos da cultura. Essa área do conhecimento vem sendo desenvolvida por estudiosos, principalmente na ex-União Soviética, mas também na Europa Central, através de uma perspectiva multidisciplinar. Ao buscar contribuições na antropologia, na neurologia, na etologia humana, entre outras áreas do conhecimento, a semiótica da cultura possibilita o diálogo entre a biologia e a cultura, procurando romper com a observação desnarrativizada, des-historicizada dos fenômenos da cultura que vigorava nos séculos XIX e XX, que buscavam o rigor e a precisão alcançados por técnicas de observação cada vez mais apuradas, possibilitadas através da descoberta de fatos e dados cada vez mais microscópicos, até mesmo na sua dimensão temporal.

Os estudiosos da semiótica da cultura introduziram os fatores macrotemporais ou simbólico-narrativos na observação dos fenômenos da cultura, por acreditarem que tanto na evolução ontogenética quanto na evolução filogenética o pensamento simbólico e narrativo é fundante do processo de hominização, sendo então fundante da cultura (Baitello Júnior, 1999).

Desse modo, em vez de ser considerada em posição antagônica à natureza, a cultura emerge da natureza e retroage sobre ela. Natureza e cultura, apesar de serem conceitos diferenciados, comunicam-se sem oposições. Nesse sentido, ao refutarmos os conceitos de cultura que a colocam em oposição à natureza, compreendemos que a cultura é o "produto de emergências de complexidades oriundas da natureza, não se distingue dessa última senão pela singularidade, sempre eventual, de uma comunicação hipercomplexa e aberta, consciente ou inconsciente. [...] É sobretudo 
marcada pela manutenção/metamorfose dos registros da memória primordial e histórica de todos os homens e de cada um deles" (Almeida, 1997, p. 39).

A cultura é constituída pelo conjunto de textos produzidos pelo homem, não apenas construções da linguagem verbal, mas também mitos, rituais, gestos, ritmos, jogos, entre outros. Os textos da cultura são considerados, também, sistemas comunicativos que obedecem às regras e normas preconizadas pela cultura vigente. $\mathrm{O}$ que não impede culturas diferentes de se comunicarem. "A cultura é o macrossistema comunicativo que perpassa todas as manifestações e como tal deve ser compreendido para que se possam compreender assim as manifestações culturais individualizadas" (Baitello Júnior, 1999, p. 18). A comunicação entre as diversas culturas permite que as criações do homem, como a música, o cinema, as danças, os jogos e os brinquedos, atravessem fronteiras.

Essas criações surgem da necessidade de perpetuar o seu criador, que morre, mas ao mesmo tempo consegue sobreviver através desses acervos, desafiando e vencendo a própria morte e os limites que a vida vai impondo. Criações que são recriadas através de novas descobertas, de novas interpretações dos indivíduos e das sociedades e vão sendo transmitidas através das gerações, dos diferentes grupos e épocas. Criações que possuem normas específicas e independentes, mas que podem se alastrar pelas diversas sociedades, permitindo as trocas culturais.

Considerando a relação entre corpo, natureza e cultura aqui apresentada, refletimos sobre os processos cognitivos e uma nova concepção de cognição que possa reconhecer a circularidade existente entre corpo e mundo, natureza e cultura.

\section{O conhecimento e a lógica recursiva}

Apresentamos elementos que configuram a cognição e a lógica recursiva no processo de produção do conhecimento por meio dos estudos da percepção. Para compreender como se processa a percepção, os estudos sobre o sistema nervoso apresentam indica- dores de uma nova compreensão sobre como ocorre a atividade cognitiva.

Merleau-Ponty (1990) problematiza a idéia de considerar a percepção como uma operação intelectual compreendida através da decodificação de estímulos advindos dos órgãos dos sentidos. Nela, a sensação, ao ter a função de instrumento que possibilita a consciência apreender um objeto, é concebida como sendo distinta da percepção. Para tanto, busca subsídios na neurologia, através da revisão sobre o funcionamento do sistema nervoso.

Nessa revisão, ao pesquisar lesões no cérebro, Merleau-Ponty interroga sobre a condução do impulso elétrico através da estimulação e reação, o campo perceptivo e a localização cerebral. Ao atestar que é insuficiente a correspondência pontual entre o excitante, o mapa cerebral e a reação, passa a associar a percepção ao movimento, à atitude do corpo (Nóbrega, 1999).

A percepção, na concepção de Merleau-Ponty (1999), ocorre na interação entre o sujeito e o objeto, através do entrelaçamento do corpo com a experiência vivida. Desse modo, o conceito tradicional de sensação requer, também, uma revisão, uma vez que não há diferença entre sensação e percepção para esse filósofo. A sensação não antecede a percepção, pois na própria sensação há sentido, o qual emerge no encontro com a experiência perceptiva. Existe, portanto, uma relação recíproca entre o sujeito que percebe e o objeto que é percebido.

Percebemos, então, como ocorre a interação entre o organismo, o ambiente e a cultura, o que nos faz observar que, mesmo o organismo sendo autônomo, mantém a dependência com o entorno. "Nosso corpo, enquanto se move a si mesmo, quer dizer, enquanto é inseparável de uma visão de mundo e é esta mesma visão realizada, é a condição de possibilidade, não apenas da síntese geométrica, mas ainda de todas as operações expressivas e de todas as aquisições que constituem o mundo cultural" (Merleau-Ponty, 1999, p. 519).

Nessa perspectiva, Maturana e Varela (1997) divergem do que normalmente é preconizado pela neu- 
rofisiologia e pela psicologia, fundadas nos postulados clássicos, quanto ao fenômeno da percepção ser conotado como uma operação de captação de uma realidade externa, mediante um processo de recepção de informações da realidade; o que já estava presente nas reflexões de Merleau-Ponty (1990) sobre a percepção, ao criticar a ciência em sua versão positivista.

Maturana e Varela (1997) consideram o sistema nervoso um sistema fechado, ${ }^{8}$ ou seja, funcionando como uma rede fechada de relações variáveis de atividade. Desse modo, organismo e sistema nervoso estão em diferentes domínios que interagem através dos elementos sensores e efetores. E, conforme o organismo interage com o meio através do acoplamento estrutural, o sistema nervoso gera correlações senso-efetoras que darão origem ao comportamento.

Ao fazerem críticas à representação como responsável pelo fenômeno cognitivo, Maturana e Varela (1997) pretendem substituir também a noção de input output, a qual faz do organismo um sistema de processamento de informação, base do pensamento tradicional. Para tanto, propõem, através da reciprocidade histórica, uma nova definição para mostrar a interação entre um sistema autônomo e o seu meio, passando a denominar de enacção. ${ }^{9}$

A enacção desloca o papel da representação ao considerar que o conhecimento é incorporado, isto é, refere-se ao fato de sermos corpo, com uma infinidade de possibilidades sensório-motoras, e estarmos imersos em contextos múltiplos. A enação enfatiza a dimensão existencial do conhecer, emergindo da corporeidade. A cognição depende da experiência que acontece na ação corporal. Essa ação vincula-se às capacidades sensório-motoras, envolvidas no

8 Para o operar do sistema nervoso quando este é considerado fechado, não existe dentro nem fora; ele apenas vai mantendo as correlações que lhe são próprias, as quais estão em contínua mutação (Maturana \& Varela, 2001).

9 Esta palavra é um neologismo inspirado no inglês enaction; é utilizada com o intuito de trazer à mão, de fazer emergir (Maturana \& Varela, 1997). contexto biopsicocultural. O termo significa que os processos sensoriomotores, percepção e ação são essencialmente inseparáveis da cognição. (Nóbrega, 1999, p. 106)

A enação tem como princípio lógico a recursividade, através da qual transcende o limite da linearidade, o que garante a dinâmica das interações entre o todo e as partes, capaz de gerar autonomia, característica marcante dos sistemas autopoiéticos. Portanto, sendo a cognição inseparável do corpo, concebendo o conhecimento como interpretação que surge da relação entre a pessoa e o mundo deixamos de lado a idéia da imagem mental do mundo, observado através do processamento de informações.

Na perspectiva da autopoiese, refuta-se também a concepção tradicional da fisiologia clássica, na qual o movimento era ocasionado por estímulos advindos do meio ambiente através do esquema estímulo-resposta, e onde os órgãos dos sentidos e suas fibras aferentes levavam o estímulo ao sistema motor, utilizando as fibras eferentes para processar e executar a resposta. Nessa concepção, há uma modificação na relação entre os sistemas aferente e eferente; passa-se, então, a requerer a reflexão, o que possibilita a atribuição de diferentes significados a um mesmo fenômeno, predominando uma certa clausura operacional. ${ }^{10} \mathrm{Em}$ vez de ocorrer o determinismo do ambiente, o próprio sistema possui condições de operar, estando aberto para trocas com o entorno e gerando diversas possibilidades de respostas, com base na circularidade ou recursividade dos fenômenos (Nóbrega, 1999).

Essa preocupação em considerar o organismo como sistema dinâmico, complexo, com conexões diretas com o ambiente, tem sido abordada também por Jarvilheto (2001), ao demonstrar que a percepção une partes novas do ambiente para o sistema organismoambiente, possibilitando que o conhecimento seja for-

${ }^{10}$ Este termo é proposto para caracterizar uma nova forma de interseção mediada pela autonomia do sistema. Refere-se à operação que ocorre no interior de um espaço de transformação (Maturana \& Varela, 1997). 
mado pela percepção através de uma reorganização desse sistema, em vez de ocorrer pela transmissão de informação do ambiente.

O conhecimento depende da existência do mundo, o qual é inseparável do nosso corpo, da nossa linguagem e da nossa história social. O conhecimento é o resultado da interpretação contínua que emerge da nossa capacidade de compreender, e essa capacidade é originada nas estruturas do nosso corpo através de experiências de ação que vão surgindo ao longo da nossa história cultural (Varela et al., 1996). Dessa maneira, conhecer, fazer e viver não podem ser considerados de modo estanque, e tanto a realidade em que vivemos quanto a nossa identidade móvel, ou seja, nosso corpo, fazem parte dessas construções.

Essa lógica recursiva se aproxima da noção de reversibilidade dos sentidos que Merleau-Ponty (1999) já propunha ao referir-se à comunicação entre eles. Nesta, há um entrelaçamento entre o vidente e o visível, o tangente e o tangível, pois o mesmo corpo que vê e toca pertence ao mesmo mundo do visível e do tangível. O sentir é compreendido na aderência do sentiente ao sentido e do sentido ao sentiente, como na reversibilidade do aperto de mãos, quando, ao mesmo tempo que toca, pode sentir-se tocado. Essa lógica recursiva aponta para um novo sentido epistemológico que diz respeito à reflexão corporal, uma epistemologia que acontece nos processos corporais.

A noção de reversibilidade dos sentidos é imprescindível para compreendermos a dinâmica do corpo em movimento. Nessa ótica não se atribui mais um espaço ordenador à consciência, mas através da comunicação entre os sentidos, passamos a compreender a circularidade entre os processos corporais e estados neuronais, entre corpo e mente (Nóbrega, 1999).

Ao falar a respeito da aprendizagem de movimentos nessa perspectiva, Nóbrega mostra que:

[...] quando nos movimentamos, informamos ao corpo sobre os acontecimentos do meio ambiente, bem como a respeito dos acontecimentos do próprio corpo, ao mesmo tempo, agimos sobre o ambiente. Podemos chamar esse processo de percepção. De certa forma, esses movimentos tornam-se "automáticos", ou seja, tão logo os tenhamos aprendido, não precisamos mais "pensar sobre eles" para os executarmos. O corpo sabe! (idem, p. 109)

A autora refere-se ainda à reorganização do corpo, ao explicitar que não é possível a realização de dois movimentos iguais, pois o corpo e sua estrutura perceptiva ${ }^{11}$ estão o tempo todo se reorganizando, mas, por serem microprocessos, não conseguimos notar. Para quem está observando, ou seja, no macroprocesso, parece que não há novidades; embora no microprocesso apareçam sempre novas interpretações para o movimento, há renovação ininterrupta (idem).

Assim, refletimos sobre algumas possibilidades do corpo em movimento. Corpo que salta, que dança, que joga, que corre, que ginga, que caminha ou que nada. Que pisca e se estica, que rola e se enrosca, que vibra e sacode. Que foge. Corpo que ri, que chora, que grita, que sofre e goza. Corpos que se expressam fazendo aflorar as diversidades de sentidos criadas a partir do movimento.

O corpo é nossa possibilidade de existência. Imperfeito, maravilhoso; ao mesmo tempo em que se mostra, esconde muito do que é registrado durante suas vivências, sendo capaz de questionar as separações e fixações impostas pela ciência clássica. ${ }^{12}$ Incapaz de apresentar respostas preestabelecidas como uma máquina, ${ }^{13}$ pois para o ser vivo a aquisição de um hábito verdadeiro é a incorporação de uma forma suscetível de transformar-se. Em contrapartida, a máquina executa "uma montagem prevista para um número finito

${ }^{11}$ Na estrutura perceptiva não há divisão entre sensório, motor, intelecto; entre sensação e percepção; entre aferentes e eferentes.

12 As críticas à ciência clássica referem-se aos dualismos, à concepção de corpo como objeto e à causalidade linear.

${ }^{13}$ A máquina a que estamos nos referindo neste trabalho está relacionada às máquinas que tinham essencialmente o mecanismo de relógio, cujo modelo foi utilizado para fundamentar a fisiologia mecanicista do século XVII; portanto, não estamos fazendo referência às modernas máquinas cibernéticas. 
de casos. A margem de imprevisto da máquina é muito reduzida. A máquina funciona, o animal vive, ou seja, ele reestrutura seu mundo e seu corpo" (MerleauPonty, 2000, p. 264). Corpo capaz de revelar o "ser selvagem", o "ser do abismo" marcado por infinitas transformações. Um ser que, ao invés de ficar fixo, modifica-se constantemente (Merleau-Ponty, 1980).

Para compreender a lógica dinâmica, que a coloca em constante transformação, capaz de se autoorganizar, acreditamos ser necessário unir domínios separados, inclusive entre humanidade e animalidade, natureza e cultura, corpo e mente, razão e emoção, conceitos considerados antagônicos, recusar a causalidade linear e caminhar na busca da superação dos dualismos e dos determinismos de toda ordem.

Nesse sentido, pensar sobre a natureza do corpo é pensar que, ao ser natureza, o corpo orgânico ${ }^{14}$ é também cultural. "Enigma do corpo, coisa e medição de todas as coisas, fechado e aberto, tanto na percepção quanto no desejo - não duas naturezas nele, mas dupla natureza: o mundo e os outros tornam-se nossa carne" (Merleau-Ponty, 2000, p. 341).

Uma carne que não significa matéria, espírito, nem substância, mas refere-se à maneira de ser na aderência ao espaço e ao tempo. A carne do corpo se propaga para a carne do mundo, e a do mundo para a do corpo, numa reversibilidade constante. Da reversibilidade que permite o enovelamento entre corpo e mundo é que nasce a percepção. Concebida como experiência vivida através do corpo em movimento, a percepção aflora sentidos diversos, o que faz MerleauPonty (1999) afirmar que a relação corpo-mundo é estesiológica. Nessa relação, a comunicação entre diferentes corpos ocorre através do jogo dos sentidos.

${ }^{14}$ As palavras orgânico e organismo são de origem aristotélica. Oriundas do termo organon, referem-se à forma do corpo vivo se organizar, por ser considerado animado. No entanto, o conceito de organismo foi sendo substituído pelo conceito de máquina animal no decorrer do século XVIII, sob a influência da fisiologia mecanicista (Canguilhem, 1977).
Para Cyrulnik (1997), o corpo humano tem necessidade de estar com outros corpos a fim de que consiga ser ele mesmo, o que nos faz atentar sobre o que denomina de encantamento do mundo; ou seja, sobre a força que leva o ser humano a estar com outros corpos, através do processo contínuo da vida humana. Essa necessidade de estar com o outro é uma constante, pois, quando estamos sozinhos, o mundo esvazia-se. A ligação entre os corpos, além de provocar prazer, também pode trazer dor, angústia, desejo ou carência. O estar com o outro, como aponta o autor, ocorre entre dois indivíduos que se ligam pelos poros através de um acontecimento sensorial e afetivo, destacando que a sensorialidade humana vai se modificando conforme o organismo vai se desenvolvendo, e mediante as experiências que vão ocorrendo no mundo em que está inserido.

Enfatizamos que essa compreensão de cognição como um acontecimento da ordem da percepção e, portanto, do corpo, pode redimensionar o modo como o conhecimento é compreendido e produzido nas práticas educativas.

\section{Apontamentos para a educação}

A leitura sobre a relação entre corpo, natureza e cultura faz ressaltar alguns apontamentos para refletirmos sobre possíveis contribuições para a educação, dentre os quais destacamos: o conceito de aprendizagem; a linguagem do corpo como um conhecimento pautado numa lógica sensível; a historicidade do corpo e as condutas éticas.

A discussão realizada sobre a construção teórica da relação entre os conceitos de corpo, natureza e cultura poderá fornecer elementos para a construção de uma base epistemológica que articule argumentos para se pensar a educação a partir da compreensão do corpo humano na sua relação com o ambiente, cultura e sociedade em que vive, bem como o fenômeno da cognição como um texto corporal.

A possibilidade de estabelecer aproximações epistemológicas entre as ciências naturais, humanas e a filosofia poderá contribuir com a educação para 
que esta reconheça a polissemia do corpo e a necessidade de buscar o diálogo entre as diversas áreas do conhecimento, em vez de operar pela fragmentação dos saberes e práticas, e pela fragmentação do próprio sujeito em corpo e mente.

Diante da convergência do pensamento dos autores tematizados que problematizam as oposições inconciliáveis, pensamos que a educação, ao perceber que corpo, natureza e cultura se interpenetram através de uma lógica recursiva, ao compreender que o corpo é uma construção biocultural, um corpo vivo, e ao compreender que os opostos, em vez de se isolarem se complementam, poderá redimensionar as concepções tradicionais de educação pautadas numa visão mecanicista, que, ao buscarem a homogeneização dos corpos, concebem o aluno como um ser passivo, capaz de decodificar os estímulos do professor através de respostas preestabelecidas.

A educação, ao refutar os determinismos, sejam naturais ou culturais, e ao reconhecer que o conhecimento emerge do corpo a partir das experiências vividas, como observamos nos conceitos propostos por Merleau-Ponty, Maturana, Varela, e nos estudos dos outros autores com os quais dialogamos, poderá perceber tanto a autonomia do corpo quanto a sua dependência com o meio, a cultura e a sociedade em que vive. Nesse contexto, considera-se que na própria ação já há cognição, tendo em vista que a aprendizagem emerge do corpo a partir das suas relações com o entorno. Essa concepção de aprendizagem problematiza, portanto, a concepção intelectualista pautada nos pressupostos racionalistas da modernidade, a qual concebe o corpo e os sentidos como instrumentos no processo de conhecimento, ou então como responsáveis por enganos, por erros, sendo então descartados ou considerados acessórios no processo de construção do conhecimento.

Essas reflexões podem contribuir com a educação para o reconhecimento da linguagem do corpo como possibilidade de conhecimento. Um conhecimento pautado numa lógica sensível que emerge do corpo e é revelada no movimento que é gesto, lingua- gem do corpo em sua polissemia biocultural e histórica. Destaca-se, ainda, que o sensível referido nessa proposição não pode ser comparado ao sensível presente nos pressupostos do empirismo, haja vista que este último é base para o positivismo e continua considerando o corpo como elemento acessório para o conhecimento. O sensível aqui tematizado, baseado na concepção fenomenológica, advém da interação entre sujeito e objeto do conhecimento, manifesta-se nos processos corporais onde ocorre a percepção. Ao mesmo tempo em que contém significações que singularizam o sujeito, permite a intercomunicação com a singularidade do outro, sendo considerado também base para a construção do conhecimento.

Pensar uma nova agenda do corpo na educação em geral e na escola em particular é inicialmente compreender que o corpo não é um instrumento das práticas educativas; portanto, as produções humanas são possíveis pelo fato de sermos corpo. Ler, escrever, contar, narrar, dançar, jogar são produções do sujeito humano que é corpo. Desse modo, precisamos avançar para além do aspecto da instrumentalidade. $\mathrm{O}$ desafio está em considerar que o corpo não é instrumento para as aulas de educação física ou de artes, ou ainda um conjunto de órgãos, sistemas, ou ainda o objeto de programas de promoção de saúde ou lazer. Certamente, áreas como educação física ou artes tematizam práticas humanas cuja expressão, em termos de linguagem, tem no corpo sua referência específica, como é o caso da dança ou do esporte.

A gestualidade ou os cuidados com o corpo podem e devem ser tematizados nas diferentes práticas educativas propostas nos currículos e viabilizados por diferentes disciplinas. O desafio está em superarmos o aspecto instrumental, que, geralmente, caracteriza boa parte das abordagens sobre o corpo na educação, notadamente as que guardam relações muito estreitas com a cultura do corpo divulgada no ideário da escola nova, nos métodos ginásticos ou no movimento de esportivização, entre outros projetos educativos. Embora possamos nos referir a experiências significativas nesse campo, há muitos desafios a serem supera- 
dos, notadamente no que se refere à superação da instrumentalidade e compreensão da corporeidade ${ }^{15}$ como princípio epistemológico capaz de ressignificar nossas paisagens cognitivas e alterar metas sociais e educativas.

Destacamos ainda que a educação, ao perceber que corpo, natureza e cultura se interpenetram através de uma lógica recursiva, poderá compreender que o corpo natural é cultural, humano e animal, universal e singular, portanto, histórico. Logo, ao perceber que não é possível ir em busca de um corpo isento de história e ao reconhecer a responsabilidade que possui ao colaborar com a reescrita dessa história, ela tem o desafio de permitir desabrochar as subjetividades, abrindo espaços que possibilitem aflorar o ser selvagem, o ser do abismo, um ser que, ao se modificar constantemente, provoca mudanças no ambiente, na sociedade, na cultura. Uma educação que seja capaz de fazer desvendar a capacidade criativa de um corpo que, ao viver, se reestrutura mediante imprevistos, fazendo desvelar a complexa condição humana.

A educação poderá reconhecer tanto as diversidades individuais e culturais como a possibilidade de comunicação entre os seres humanos, podendo refutar a hierarquização entre as diferentes culturas, como defende Lévi-Strauss. Desse modo, os professores poderão abrir espaço para que os alunos possam refletir sobre suas individualidades, sobre a sociedade em que estão inseridos, permitindo também o reconhecimento da variedade de culturas e a possibilidade de diálogo entre elas.

O desafio faz-se presente e urgente. Redimensionar as práticas pedagógicas na perspectiva de condutas éticas poderá colaborar com novas possibilidades de intervenção, contribuindo com a problematização da visão antropocêntrica que promove o isolamento e a incomunicabilidade capazes de deteriorar as formas de sociabilidade. Redimensionar as práticas pedagógicas a partir de uma educação pautada em valores que

${ }^{15}$ Para um detalhamento dessa compreensão de corporeidade, consultar Nóbrega (1999). promovam a compreensão e a autonomia; uma educação preocupada com a vida, com o próprio corpo e com o corpo do outro, configurando possibilidades de novas formas de ser, de viver, de movimentar-se.

Essa compreensão do conhecimento como texto corporal poderá possibilitar intervenções na educação que problematizem concepções segregadoras de corpo, movimento, natureza, cultura, e do próprio conhecimento. Uma educação que desperte o desejo, a solidariedade do estar com o outro numa sociabilidade comunicativa. Uma educação que considere que o corpo é carne do mundo, numa relação ética e estética que ultrapassa a racionalidade instrumental e as lógicas redutivas dos processos de construção do conhecimento.

\section{MARIA ISABEL BRANDÃO DE SOUZA MENDES, mes-} tre em educação pela Universidade Federal do Rio Grande do Norte (UFRN), é doutoranda em educação pela mesma universidade e pesquisadora do Grupo de Estudo Corpo e Cultura de Movimento (GEPEC). Publicou: Educação Física: prisioneira do século XIX? (Revista Brasileira de Ciências do Esporte, Campinas, CBCE, v. $25, n^{\circ} 2$, p. 85-96, jan. 2004); Corpo, biologia e educação física (Revista Brasileira de Ciências do Esporte, Campinas, v. 24, $\mathrm{n}^{\circ} 1$, p. 9-22, set. 2002). No prelo: Cultura de movimento e educação do corpo: um olhar sobre a Vila de Ponta Negra (Revista Educação em Questão, Natal, EDUFRN).E-mail: medsek@ @erra.com.br

TEREZINHA PETRUCIA DA NÓBREGA, doutora em educação pela Universidade Metodista de Piracicaba (UNIMEP), é professora do Programa de Pós-Graduação em Educação da Universidade Federal do Rio Grande do Norte (UFRN). No Grupo de Estudo Corpo e Cultura de Movimento (GEPEC), pesquisa a temática: Corpo e epistemologia. Entre livros e artigos publicados, destacam-se: Corporeidade e educação física: do corpo-objeto ao corpo-sujeito (Natal: EDUFRN, 2000); Corpos do tango: reflexões sobre gestos e cultura de movimento, In: LUCENA, Ricardo de F., SOUZA, Edilson Fernandes de (orgs.). Educação Física, esporte e sociedade (João Pessoa, EDUFPB, 2003); Corpo, estética e conhecimento, In: ALMEIDA, Maria da Conceição et al., Polifônicas idéias: por uma ciência aberta (Porto Alegre: Sulinas, 2003).E-mail: pnobrega@ufrnet.br 


\section{Referências bibliográficas}

ALMEIDA, M. da C., (1997). Complexidade, do casulo à borboleta. In: CASTRO, G. de et al. (orgs.). Ensaios de complexidade. Porto Alegre: Sulina, p. 25-45.

BAITELlO JUNIOR, N., (1999). Síndrome da máquina. In: CASTRO, G. de et al. (orgs.). Ensaios de complexidade. Porto Alegre: Sulina, p. 115-121.

CANGUILHEM, G., (1977). Ideologia e racionalidade nas ciências da vida. Portugal: Edições 70. Tradução de Emília Piedade.

CYRULNIK, B., (1997). Do sexto sentido: o homem e o encantamento do mundo. Lisboa: Instituto Piaget. Tradução de Ana Rabaça.

FOUCAULT, M., (1987). Vigiar e punir: nascimento da prisão. Petrópolis, Vozes. Tradução de Raquel Ramalhete.

JARVILEHTO, T., (2001). Efferent influences on receptors in knowledge formation. Target article by Jarvilehto on efference knowledge. Disponível em: <http://www.edu.oulu.fi/homepage/ tjarvile>. Acesso em: $15 \mathrm{dez} .2003$.

LÉVI-STRAUSS, C., (1976). As estruturas elementares do parentesco. Petrópolis: Vozes; São Paulo: EDUSP. Tradução de Mariano Ferreira.

, (1983). O olhar distanciado. São Paulo: Martins Fontes. Tradução de Carmen de Carvalho.

MATURANA, H., (2001). Cognição, ciência e vida cotidiana. Belo Horizonte: Editora da UFMG. Tradução de Cristina Magro e Victor Paredes.

MATURANA, H., VARELA, F., (1997). De máquinas e seres vivos: autopoiese - a organização do vivo. $3^{\mathrm{a}}$ ed. Porto Alegre: Artes Médicas. Tradução de Juan Acuña Llorens. , (2001). A árvore do conhecimento: as bases biológicas do entendimento humano. Campinas: Editorial Psy II. Tradução de Jonas Pereira dos Santos.

MERLEAU-PONTY, M., (1980). Textos escolhidos. São Paulo: Abril Cultural. Seleção e tradução de Marilena de Souza Chauí. , (1990). O primado da percepção e suas conseqüên- cias filosóficas. Campinas: Papirus. Tradução de Constança Marcondes Cesar.

, (1991). Signos. São Paulo: Martins Fontes. Tradução de Maria Ermantina G. G. Pereira.

(1999). Fenomenologia da percepção. $2^{a}$ ed. São Paulo: Martins Fontes. Tradução de Carlos Alberto Ribeiro de Moura.

, (2000). A natureza: notas: cursos no Collège de France. São Paulo: Martins Fontes. Tradução de Álvaro Cabral. MORIN, E., (1973). O paradigma perdido: a natureza humana. $5^{\mathrm{a}}$ ed. Lisboa: Publicações Europa-América. Tradução de Hermano Neves.

(1977). O método I: a natureza da natureza. Lisboa: Publicações Europa-América. Tradução de Maria Gabriela de Bragança.

, (1980). O método II: a vida da vida. $2^{\mathrm{a}}$ ed. Lisboa: Publicações Europa-América. Tradução de Maria Gabriela de Bragança.

NÓBREGA, T. P., (1999). Para uma teoria da corporeidade: um diálogo com Merleau-Ponty e o pensamento complexo. Tese de doutorado. Universidade Metodista de Piracicaba. , (2000). Corporeidade e educação física: do corpo objeto ao corpo-sujeito. Natal: EDUFRN.

PONTES, H., (1999). Os mistérios do número 8 e a aula inaugural de Lévi-Strauss no Collège de France. In: CATANI, A. M., MARTINEZ, P. H. (orgs.). Sete ensaios sobre o Collège de France. São Paulo: Cortez, p. 43-59.

SHELDRAKE, R., (1991). O renascimento da natureza: o reflorescimento da ciência e de Deus. São Paulo: Cultrix. Tradução de Maria de Lourdes Eichenberger e Newton Roberval Eichemberg.

VARELA, F. et al., (1996). The embodied mind: cognitive science and human experience. $5^{\mathrm{a}}$ ed. London, England: MIT Press.

Recebido em outubro de 2003 Aprovado em fevereiro de 2004 
the adults of our study, school world and daily life world were represented as separated, as well as the mathematical knowledge generated in each of these contexts.

Key-words: ethnomathematics; adult basic education; quantitative and spatial representations

Maria Isabel Brandão de Souza Mendes e Terezinha Petrucia da Nóbrega

\section{Corpo, natureza e cultura:} contribuições para a educação Ao se discutir a construção teórica da relação entre os conceitos de estes conceitos, busca-se apontar possíveis contribuições para a educação. Ao conceber que estes conceitos se interpenetram através de uma lógica recursiva, que o corpo é uma construção biocultural, um corpo vivo, e ao compreender que os opostos, em vez de se isolarem, se complementam, se poderá reconhecer tanto a autonomia do corpo quanto a sua dependência com o meio, a cultura e a sociedade em que vive. Desse modo, a educação, ao perceber que não é possível ir em busca de um corpo isento de história, e ao reconhecer a responsabilidade que possui ao colaborar com a reescrita dessa história, tem o desafio de permitir desabrochar as subjetividades, abrindo espaços que possibilitem aflorar um ser que, ao modificar-se constantemente, provoca mudanças no ambiente, na sociedade, na cultura.

Palavras-chave: corpo; educação; epistemologia; natureza; cultura

\section{Body, nature and culture:} contributions for education In discussing the theoretical construction of the relation between the concepts of body, nature and culture, this article seeks to point to possible contributions for education. By conceiving that body, nature and culture are interwoven by a recursive logic, that the body is a biocultural construction, a living body, and by understanding that the opposites, instead of isolating themselves, complement each other, it should be possible to recognise both the autonomy of the body and its dependence on the environment, culture and the society in which it resides. In this way, by perceiving that it is not possible to look for a body exempt from history, and by recognising the responsibility which it has in collaborating with a rewriting of that history, education faces the challenge of permitting subjectivities to blossom, opening spaces which will allow a being to bloom who, by constant modification, provokes changes in the environment, society and culture.

Key-words: body; education, epistemology; nature; culture

Sonia Maria Rummert

Programa Integração: avanços e contradições de uma proposta de educação formulada pelos trabalhadores

Este artigo analisa o Programa Integração, desenvolvido pela Central Única dos Trabalhadores (CUT), no âmbito do Programa de Qualificação Profissional (PNQP). Aborda especificamente o caso do Programa Integração do Sindicato dos Trabalhadores em Telecomunicações do Rio de Janeiro, focalizando a problemática das telecomunicações no Brasil e suas repercussões junto aos trabalhadores e às suas entidades representativas. São também abordadas as contradições inerentes à opção da CUT pelo papel de executora de uma política de educação dos trabalhadores, materializada no Programa Nacional de Qualificação Profissional (PLANFOR), implementada pelo Estado, sob a hegemonia do ideário neoliberal. São analisados também os avanços e os limites das contribuições teórico-metodológicas do Programa Integração à educação de jovens e adultos trabalhadores, dando especial relevo às suas potencialidades.

Palavras-chave: educação básica e profissional de jovens e adultos trabalhadores; movimento sindical e educação; fundamentos teórico-metodológicos da educação de jovens e adultos trabalhadores.

Integration Programme: advances and contradictions in an educational proposal formulated by workers

The text analyses the Integration Programme, developed by the Workers Central Trade Union Organisation (CUT), within the context of the Programme of Professional Qualification (PNQR). It deals specifically with the way in which this programme was implemented by the Telecommunication Workers' Trade Union in Rio de Janeiro, focusing on the problem of telecommunications in Brazil and its repercussions on workers and on their representative entities. The contradictions inherent in CUT's option for the role of executor of a policy of workers' education, embodied in the National Programme of Professional Qualification (PLANFOR), implemented by the State under the hegemony of neoliberal inspiration are also discussed. The advances and limitations of the theoretical-methodological contributions of the Integration Programme to the education of adult and young workers are also dealt with, giving special emphasis to their potential.

Key-words: primary and professional education for young and adult workers; trade union movement and education; theoretical-methodological foundations of education for young and adult workers

Mauricio Rocha

Paradoxo da formação: servidão voluntária e liberação 